\title{
Konsep Kualitas Pelayanan Kesehatan berdasar atas Ekspektasi Peserta Jaminan Kesehatan Nasional
}

\author{
Ida Hadiyati, ${ }^{1}$ Nanan Sekarwana, ${ }^{2}$ Deni Kurniadi Sunjaya, ${ }^{3}$ Elsa Pudji Setiawati ${ }^{3}$ \\ ${ }^{1}$ Dinas Kesehatan Kabupaten Bandung, ${ }^{2}$ Departemen Ilmu Kesehatan Anak Fakultas Kedokteran \\ Universitas Padjadjaran/Rumah Sakit Dr. Hasan Sadikin Bandung, ${ }^{3}$ Departemen Ilmu Kesehatan Masyarakat \\ Fakultas Kedokteran Universitas Padjadjaran
}

\begin{abstract}
Abstrak
Masyarakat memiliki hak untuk mendapatkan pelayanan kesehatan yang bermutu dan terjangkau. Sejak awal tahun 2014, pemerintah berupaya meningkatkan akses pelayanan kesehatan melalui program Jaminan Kesehatan Nasional. Pelayanan kesehatan tersebut tentunya harus tetap berkualitas. Peneliti bertujuan merumuskan konsep kualitas pelayanan kesehatan berdasar atas ekspektasi pasien. Desain penelitian ini adalah kualitatif dengan paradigma konstruktivisme. Partisipan terdiri atas 17 pasien rawat jalan peserta Jaminan Kesehatan Nasional dan 7 petugas kesehatan Rumah Sakit Umum Daerah Al-Ihsan dan Soreang Kabupaten Bandung, Pengumpulan data dilakukan dengan cara wawancara mendalam selama bulan Agustus-November 2016. Pelayanan kesehatan yang berkualitas terdiri atas 11 dimensi. Dimensi sarana prasarana mengutamakan kecukupan kapasitas fasilitas. Dimensi karyawan mengutamakan kesesuaian jumlah kapasitas tenaga kerja. Dimensi pelayanan medis mengutamakan komunikasi. Dimensi pelayanan administrasi mengutamakan sistem antrian yang tertib. Dimensi keamanan pelayanan mengutamakan minimalisasi risiko bahaya. Dimensi kepercayaan menunjukkan loyalitas. Dimensi akses mengutamakan kemudahan menjangkau rumah sakit. Dimensi kesetaraan merupakan perlakuan yang sama antara pasien peserta JKN dan non-JKN. Dimensi transparansi informasi merupakan penyajian informasi yang jelas. Dimensi iur biaya mengungkapkan tidak ada penambahan biaya dalam tindakan medis maupun pengobatan. Dimensi kualitas antar bagian merupakan pelayanan yang sama di setiap titik bagian pelayanan. Pelayanan kesehatan yang berkualitas berdasar atas harapan pasien meliputi dimensi sarana prasarana, karyawan, pelayanan medis, pelayanan administrasi, keamanan pelayanan, kepercayaan terhadap rumah sakit, akses, kesetaraan, transparansi informasi, iur bayar, dan kualitas antarbagian. [MKB. 2017;49(2):102-9]
\end{abstract}

Kata kunci: Ekspektasi pasien, Jaminan Kesehatan Nasional, kualitas pelayanan kesehatan

\section{Health Service Quality Concept based on Expectation of the National Health Insurance Participants}

\begin{abstract}
Community has the right to receive affordable and qualified health care. Since the early 2014 , the government has attempted to increase health care access through the implementation of the National Health Insurance (Jaminan Kesehatan Nasional, JKN) scheme that still requires quality health care. The aim of this study was to formulate the concept of health care quality based on patients' expection. This was a qualitative study using constructivism paradigm on $17 \mathrm{JKN}$-member outpatients and 7 health care workers of Al-Ihsan General Public Hospital and Soreang Public District Hospital, Bandung District. Data were collected through in-depth interviews during the period of August-November 2016. Quality health care consists of 11 dimensions: facility and infrastructure dimension that prioritizes on adequacy of facility capacity; employee dimension that prioritizes on the number and capacity of human resource; medical service dimension that prioritizes on communication; administrative service dimension that prioritizes on orderly queuing system; service safety dimension that prioritizes on minimizing hazard risk; trust dimension that shows loyalty; access dimension that prioritizes on easy access to hospital; equality dimension that emphasizes same treatment for JKN and non-JKN patients; information transparency that prioritizes on clear information provision; cost sharing dimension that underlines no additioanl fee for medical actions and treatments; and inter-department quality dimension that includes same services in each service point. It is revealed that quality health care based on patients' expectation includes facility and infrastrucutre, employee, medical service, administrative service, service security, trust towards hospital, access, equality, information transparency, cost-sharing, and inter-department quality. [MKB. 2017;49(2):102-9]
\end{abstract}

Key words: Health Service Quality, National Health Insurance, Patient Expectation

Korespondensi: Ida Hadiyati, dr., MM-BAT, Dinas Kesehatan Kabupaten Bandung Jalan Raya Soreang Komplek Pemda Kabupaten Bandung, 40911, E-mail: ida.hadiyati@ymail.com 


\section{Pendahuluan}

Setiap orang memiliki hak untuk mendapatkan akses pelayanan kesehatan yang berkualitas, aman, dan juga terjangkau. ${ }^{1}$ Pemerintah telah berupaya untuk meningkatkan akses pelayanan kesehatan masyarakat dengan telah mengadakan program Jaminan Kesehatan Nasional yang sudah diselenggarakan sejak Januari 2014. ${ }^{2}$ Akibat peningkatan akses pelayanan kesehatan ini terjadi peningkatan kunjungan pasien di fasilitas kesehatan, termasuk di rumah sakit. Hal ini menyebabkan pelayanan kurang optimal, ditunjukkan dengan ketidakpuasan pasien di era Jaminan Kesehatan Nasional. ${ }^{3}$ Padahal, pelayanan kesehatan yang telah diberikan di era Jaminan Kesehatan Nasional dituntut untuk tetap berkualitas. ${ }^{4}$

Beberapa dari penelitian yang terdahulu telah menggambarkan bagaimana konsep pelayanan kesehatan yang berkualitas. Konsep tersebut yaitu meliputi infrastruktur, kualitas personel, proses pelayanan klinis, proses administrasi, keamanan, kepercayaan terhadap pelayanan kesehatan, serta akses. ${ }^{5-8}$ Kepuasan timbul akibat kesesuaian antara pelayanan yang disajikan dan harapan pasien. ${ }^{9}$ Saat ini, pelayanan kesehatan yang berkualitas merupakan pelayanan yang mengacu pada preferensi, ekspektasi, dan juga kebutuhan pasien. Pandangan pasien mengenai apa yang penting bagi mereka tentang pelayanan kesehatan merupakan aspek yang penting dalam

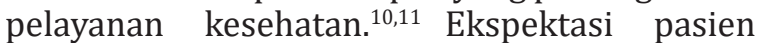
merupakan harapan pasien atas pelayanan kesehatan yang diterimanya. ${ }^{12}$ Dengan mengukur ekspektasi pasien, pelayanan yang diberikan dapat memenuhi harapan pasien. ${ }^{13}$ Oleh karena itu, perlu dilakukan suatu eksplorasi mengenai ekspektasi pasien pelayanan kesehatan yang berkualitas. $^{14}$

\section{Metode}

Desain penelitian ini adalah kualitatif dengan paradigma konstruktivisme yang dilakukan di Instalasi Rawat Jalan Rumah Sakit Umum Daerah Al-Ihsan dan Rumah Sakit Umum Daerah Soreang Kabupaten Bandung selama Bulan Agustus-November 2016. Pengumpulan data dilakukan dengan wawancara mendalam (in-depth interview) menggunakan theoretical sampling. ${ }^{15}$ Jumlah partisipan dalam penelitian ini adalah 24 orang yang terdiri atas 17 pasien rawat jalan peserta Jaminan Kesehatan Nasional dan 7 petugas kesehatan, yaitu Kepala Instalasi
Rawat Jalan, Kepala Ruangan Rawat Jalan, dan Kepala Subseksie Rekam Medik, Kepala Instalasi Farmasi. Penelitian ini telah melalui izin Komite Etik Fakultas Kedokteran Universitas Padjadjaran dengan Nomor 835/UN6.C1.3.2/ KEPK/PN/2016. Data yang telah diperoleh dilakukan trustworthiness dengan melaksanakan kredibilitas, transferabilitas, dependabilitas, serta konfirmabilitas. ${ }^{16,17}$ Data yang telah didapat dilakukan proses transkripsi, reduksi. Interprestasi data dengan melakukan koding, kemudian kategorisasi untuk diklasifikasikan menjadi beberapa kategori yang selanjutnya dilakukan teorisasi. ${ }^{17}$

\section{Hasil}

Wawancara mendalam dilakukan terhadap 17 pasien rawat jalan peserta Jaminan Kesehatan Nasional yang terdiri atas $67 \%$ perempuan dan $33 \%$ laki-laki. Usia partisipan dalam rentang 21-30 tahun sebanyak 7\%, rentang 31-40 tahun sebanyak $13 \%$, sedangkan rentang $41-$ 50 tahun dan 51-60 tahun masing-masing sebanyak $40 \%$. Pendidikan terakhir partisipan mayoritas Sekolah Menengah Atas sebanyak $47 \%$. Pendidikan terakhir Sekolah Dasar, D1, dan S-1 masing-masing 14\%, sedangkan pendidikan terakhir D-3 dan S-2 masing-masing 5,5\%.

Dari hasil wawancara mendalam didapatkan 11 kategori, mencakup dimensi pelayanan kesehatan yang berkualitas. Berdasar atas hasil analisis data, hampir seluruh dimensi yang telah dikaji sebelumnya oleh peneliti diungkapkan oleh informan dari proses eksplorasi. Selain itu, muncul pula beberapa dimensi baru, yakni kesetaraan, kualitas antarbagian, transparansi, serta iur bayar. Berdasarkan atas hasil eksplorasi terhadap pasien, terdapat empat komponen yang termasuk dalam dimensi sarana prasarana dari pelayanan kesehatan yang berkualitas. Komponen tersebut ialah kelengkapan fasilitas dan obat, kebersihan ruangan dan fasilitas, kapasitas ruangan dan fasilitas, serta keberadaan fasilitas penunjang di rumah sakit. Desain dan penampilan bangunan rumah sakit tidak menjadi prioritas bagi pasien.

"Bangunannya, mungkin segini mah cukup lah." (p2)

“Tidak terlalu kalau fisik gedung...” (p14)

Kelengkapan obat dan alat-alat kesehatan merupakan hal penting yang diharapkan oleh 
pasien. Beberapa informan merasa kecewa akibat obat yang terdapat di apotek rumah sakit tidak lengkap. Hal ini menyebabkan pasien mengeluarkan biaya tambahan untuk membeli obat di apotek luar rumah sakit.

“...ya obat pengen lengkap lah...” (p1)

"Ada beberapa kali yang tidak lengkap sehingga saya harus beli di luar." (p1)

“Jangan sampai mestinya beli lagi di luar." (p1)

"Obat kadang-kadang suka tidak ada juga sebagian. Harus beli di luar." (p5)

"Yang paling penting pertama alat-alatnya, terus pelayanannya harus memuaskan masyarakat. Kebersihannya. Dan obat-obatannya." (p8)

"Gedung nggak, nggak berpengaruh. Yang penting fasilitas pelayanannya." (p8)

"Harapannya jadi kalau obatnya tidak ada, jangan dokter...jangan memberikan resep.” (p10)

Kebersihan ruangan dan peralatan juga merupakan aspek yang dinilai penting oleh pasien. Terdapat petugas kebersihan yang selalu terlihat membersihkan ruangan dinilai positif karena menunjukkan upaya pemeliharaan kebersihan ruangan secara terus menerus.

“...mukenanya tidak bersih gitu sama kamar mandinya bau (tertawa) karena kan ini rumah sakit Islam gitu ya, identik dengan kebersihan tapi untuk kamar mandi di sini, masih pada bau sama mukenanya, kalau untuk masjid disana sih bagus bersih karena saya suka lihat yang ngepel, tapi kalau yang di ruang-ruang gini coba aja di cek kamar mandinya bau, tidak nyaman (tertawa)..." (p1)

"Kamar mandi sih bau ya (tertawa) kamar mandi kurang bersih." (p1)

"Selalu ada petugas yang membersihkan ruangan..." (p8)

“...yang di UGD pernah parah pisan gitu toiletnya teh, bau, kotor kayaknya gak layak gitu ya..." (p14)

Peningkatan pengunjung rumah sakit di era Jaminan Kesehatan Nasional ini membuat pasien berharap agar rumah sakit melakukan penyesuaian kapasitas ruangan dan fasilitas dengan jumlah kunjungan. Kapasitas tersebut di antaranya termasuk kapasitas toilet dan fasilitas ibadah seperti mushola.

"Ruang tunggu ketika banyak mah pengap..." (p1)

"Ya ketika banyak orang pengap karena semua kursi terisi kadang banyak yang berdiri kadang saya suka nunggu di luar karena pengap..." (p1)

“Kamar mandi ya perlu ditambah..." (p5)

"Toilet bisalah ditambahlah gitulah karena kalau ini suka antri kalau ke toilet itu gitu loh." (p6)

“...harus bersih harus enak duduknya juga cukup jangan ada yang berdiri..." (p12)

"Jadi tidak seimbang antara pasien dan rumah sakit." (p10)

Pasien menilai aspek penting dari karyawan digambarkan sebagai responsivitas, empati, keramahan, kompetensi, serta kapasitas sumber daya manusia. Penampilan fisik tenaga kesehatan tidak menjadi prioritas bagi pasien.

"Seragam sepertinya sudah cukup ya karena kalau yang namanya di rumah sakit tidak mewah, tapi standar aja lah pakai baju gitu ya, biasa aja sudah cukup." (p1)

Responsivitas ini, menurut pasien diharapkan diterapkan pada seluruh tenaga kerja rumah sakit, tidak hanya dokter, tetapi juga paramedis serta tenaga penunjang lainnya. Dalam kondisi sakit dan membutuhkan pertolongan medis, pasien tentunya berharap tenaga kerja di rumah sakit mampu berempati. Mereka berharap seluruh tenaga kerja rumah sakit harus dapat memahami kondisi tidak nyaman yang dialami pasien. Hal ini juga berhubungan dengan keramahan yang diharapkan oleh pasien karena keadaan tersebut menunjukkan bahwa tenaga kerja berempati terhadap pasien dan dapat memberikan kenyamanan pada pasien.

"Kadang-kadang ada suster yang judes, sampai saya komplain apakah karena saya menggunakan fasilitas BPJS sehingga kasarnya sih perlakuan anda seperti ini terhadap saya? Kasarnya mungkin ya saya gak ngerti padahal pasien itu kan orang sakit, sementara mereka orang sehat, yang harus memperlakukan itu bukan hanya 
perlakuan secara medis tapi secara naluri secara apa ya secara itu juga harus diperlakukan enak lah" (p1)

"Sopan lah gitu" (p1)

"Petugas cepat tanggap istilahnya." (p6)

"...tapi ya memang apa kurang ramah gitu ya..." (p14)

"Saya berharap petugas memiliki keterampilan yang sesuai dengan bidang yang digeluti." (p12)

"Terus dari pelayanannya juga kurang cepat, kurang bagusnya dari pelayanannya kesigapan terhadap pasiennya kurang terus keramahannya juga kurang gitu." (p14)

"Kalau banyak yang minta ini, minta itu teh, responsnya teh ya judes gitu, kalau kita teh ada keperluan, mbak gini-gini, judes aja gitu teh, kurang cekatan, minta tolong misalkan, oh dia teh kayak yang gak mau gitu, minta tolong teh gak respons gitu." (p14)

Selain itu, pada era JKN ini, terjadi peningkatan jumlah pengunjung rumah sakit. Pasien berharap tenaga kerja perlu ditambah agar rasio tenaga kerja dengan pasien menjadi sesuai.

“...cuman kurang aja sih, kurang personel..." (p2)

“Harusnya ditambah juga tuh pegawai..." (p2)

"Harapannya lagi-lagi dokternya diperbanyak..." (p5)

"Rumah sakit sekarang ini terlalu...terlalu banyak pasiennya..." (p10)

"Pasiennya terlalu banyak. Sampai dokter kewalahanlah..." (p10)

"Saya berharap jumlah perawat yang menangani pasien sebanding dengan banyaknya pasien." (p12)

“...berharap juga jumlah petugas obat itu harus lebih banyak." (p12)

Aspek yang perlu diperhatikan pada pelayanan medis adalah komunikasi. Informan berharap tenaga kesehatan dapat memberikan informasi mengenai penyakit pasien secara jelas. Informan juga berharap bahwa tenaga medis menjelaskan terlebih dahulu setiap tindakan yang akan dilakukan dan memberitahukan risiko yang mungkin terjadi dari tindakan tersebut serta cara penanggulangannya. Penjelasan mengenai penanganan penyakit di rumah dan pola hidup sehat untuk menjaga kesehatan juga diharapkan informan. Tidak hanya tenaga medis yang diperhatikan, petugas obat pun diharapkan dapat memberikan penjelasan yang jelas mengenai cara minum obat atau cara pemakaian obat serta efek samping obat yang mungkin terjadi beserta cara penanggulangannya.

“...harusnya kalau misalnya ini apa, harus dikasih tau pasiennya dulu deh gimana gitu kan. Efek sampingnya apa, dikasih tau. Misalkan, akibat nanti ke depannya gimana, jadi tahu gitu kan." (p2)

"Dokter juga harus memberikan waktu yg cukup untuk saya bertanya." (p12)

"Butuh penjelasan bu, jadi tindakannya apa, kalo ditindak ada efek samping engga, kemudian kalo ditindak nanti saya tuh bagaimana." (p12)

“...untuk pencegahan dan penanganan di rumah juga pola hidup yang sehat." (p12)

"Ketika pasien bertanya menjelaskan gitu, gak grusuk-grusuk gak cepat-cepat." (p14)

Aspek yang paling menjadi perhatian informan pada dimensi ini adalah waktu tunggu, baik itu pada proses pendaftaran, pemeriksaan dokter, pemeriksaan laboratorium, serta pengambilan obat. Pasien berharap waktu tunggu setiap pelayanan dapat berkurang, walaupun mereka memahami sebagai akibat dari pemeriksaan yang tidak berbiaya ini, pasien yang berkunjung ke rumah sakit menjadi semakin banyak sehingga waktu tunggu yang lama menjadi hal yang wajar. Namun, sebagian besar informan tetap berharap rumah sakit dapat membuat kebijakan untuk mengatasi masalah ini di antaranya dengan menambah tenaga kerja dan fasilitas. Selain itu, sistem antrian yang tertib juga diharapkan oleh informan, hal ini untuk menghindari kecurangan dalam pengambilan nomor antrian.

“...loket diperbanyak. Pelayanan yang mendaftarnya juga lebih cepat gitu." (p5)

"Iya di loket. Petugasnya perlu ditambah." (p6)

"Kalau bisa dokternya cepat dalam memberi pelayanannya." (p6) 
"Saya berharap petugas pendaftaran itu sigap dalam melayani." (p12)

Beberapa informan berharap agar rumah sakit perlu berupaya dalam mencegah potensi bahaya terhadap pasien, di antaranya seperti lantai tidak licin, tersedia pegangan di pinggir selasar, menginformasikan kemungkinan efek samping obat yang dapat terjadi dan memastikan keaslian obat dan vaksin.

"Dokternya teliti, yang memberikan obat itu perlu teliti kan." (p6)

"Harapannya merasa aman ketika diperiksa dan dilakukan tindakan." (p2)

"Lantai sebaiknya tidak licin, ya saya berharap ada pegangan biar gampang berjalan gitu." (p12)

"Terus sebelum pemeriksaan membersihkan tangan biar higienis, peralatannya bersih." (p12)

"Harapannya obat-obatnya bagus, aman, dan berkualitas." (p12)

Kepercayaan terhadap rumah sakit menurut informan dapat memengaruhi pemilihan tempat berobat dan terdapat loyalitas terhadap rumah sakit tertentu. Keadaan ini berhubungan dengan beberapa aspek di antaranya akibat dari rasa nyaman ketika berobat, perbaikan keluhan yang dirasakan, serta ada kejujuran manajemen rumah sakit.

"Ya itu lah harus memberi pelayanan yang baik lah karena yang namanya ketika pelayanan tidak baik, nanti akan sampai kepada orang lain akan sampai terus aja." (p1)

"Harapannya, yah mudah-mudahan rumah sakit ini bisa melayani masyarakatnya dengan baik, merasa nyaman juga." (p2)

"Berasa cocok... Kualitas hidup membaik." (p8)

“...nyaman pelayanannya, dokternya baik, ramah. Terus obatnya bagus." (p8)

“...pengobatan sudah merasa cocok." (p10)

“Harapannya pasien bisa sembuh." (p12)

Informan berharap lokasi rumah sakit terletak di tempat yang strategis yang mudah ditempuh mempergunakan transportasi umum. Selain itu, diharapkan lalu lintas menuju serta di sekitar rumah sakit pun lancar sehingga tidak menghambat pasien gawat darurat untuk mencapai rumah sakit.

"Ya, kalau untuk angkot coba jangan sampai parkir itu di depan pintu gerbang, kadang sulit sekali baik saya pakai motor atau pake mobil suka di tidit-tidit, angkot ngetemnya suka dekat dengan pintu gerbang, bahkan di pintu gerbang, sambil narik-narik itu penumpang." (p1)

"Masih banyak yang dagang-dagang pinggir jalan, terutama angkot yang suka menghalangi." (p1)

“...transportasi umum lewat ke sini semua.” (p12)

Para informan yang merupakan pasien pengguna Jaminan Kesehatan Nasional berharap tidak diperlakukan berbeda antara pasien pengguna Jaminan Kesehatan Nasional dan pasien umum yang tidak menggunakan Jaminan Kesehatan Nasional, dalam kecepatan pelayanan, ketelitian pemeriksaan, maupun perlakuan yang ramah dari para petugas di RS.

"Ya tolong lah dalam pelayanan disamakan lah, dalam arti sama aja gitu perlakukannya seperti pasien-pasien umum, gitu pengguna BPJS sebagai pasien umum, samain aja." (p1)

"Ya istilahnya ya layanilah pasien itu sebagaimana mestinya lah jangan ada perbedaan antara pasien umum dan pasien BPJS." (p1)

"Harapannya sama saja karena semua pasien, mau BPJS, mau bayar langsung atau umum ya kan sama-sama juga atau mengeluarkan dana dan ingin sehat juga." (p2)

"Saya berharap sebagai pasien BPJS diperlakukan sama lah sama pasien umum gitu dalam hal keramahtamahannya, kecepatan penerimaan, ketelitian gitu." (p12)

Pasien juga mengharapkan kualitas yang sama di setiap titik pelayanan di rumah sakit. Kepuasan yang didapat di suatu bagian pelayanan harus diiringi dengan kepuasan di bagian lainnya, bahkan seluruh bagian.

"Harapannya petugas-petugasnya baik, ramah, cepat, sigap." (p11)

"Ya bisa lebih baik, bagus lah gitu bersih-bersih 
di setiap ruangan." (p15)

"Harapannya ya memberikan pelayanan yg bagus dan berkualitas lah di setiap bagian pelayanan agar bisa nyaman." (p16)

Informan mengungkapkan perlunya papan pengumuman yang menunjukkan daftar tunggu ruang rawat inap maupun jadwal operasi yang jelas sehingga tidak menimbulkan spekulasi bermacam-macam, seperti ketidakjujuran para petugas terhadap pemberian informasi. Pasien juga berharap pengelola rumah sakit agar jujur dan terbuka, dapat menjelaskan kepada pasien hal mana yang termasuk dalam kebijakan internal manajemen rumah sakit dan hal mana yang termasuk dalam kebijakan Badan Penyelenggara Jaminan Sosial (BPJS) selaku penyelenggara Jaminan Kesehatan Nasional. Sering kali, rumah sakit cenderung melempar kesalahan kepada BPJS, padahal mekanisme tertentu ditentukan sendiri oleh pengelola.

"Mau operasi rumit karena kan ketika saya datang, nih ibu harus dijadwal dan sampai penjadwalan sampai berapa kali." (p1)

"Ruangan penuh, ruangan penuh, selalu begitu, padahal ibu lihat itu ada ruangan yang kosong,.." (p1)

"Harapannya jadwal dokter terpampang supaya jelas." (p12)

"Dibikin semodel daftar ruang pasien yg mau pulang supaya jelas bahwa pasien yang mau masuk sama keluar." (p12)

"Perlu terpampang jelas persyaratan administrasi." (p14)

Terdapat dua jenis pengguna Jaminan Kesehatan Nasional, yakni pengguna yang menerima bantuan iuran setiap bulan dari pemerintah dan pengguna yang membayar iuran setiap bulan secara pribadi. Mereka berharap biaya tersebut sudah meliputi seluruh kebutuhan medisnya. Penambahan biaya akan memberatkan baik penerima bantuan iuran yang memang sudah jelas merupakan masyarakat kurang mampu, maupun pengguna yang membayar iuran setiap bulan secara pribadi. Mereka merasa rugi jika masih harus membayar biaya tambahan padahal setiap bulan mereka harus mengeluarkan biaya untuk iuran Jaminan Kesehatan Nasional tersebut. “...dioperasi tidak bayar." (p1)

"Pokoknya yang masuk BPJS ini bisa dilayani dengan baik sehingga tidak perlu lagi mengeluarkan biaya membeli obat di luar. Kalau mungkin semua obat sudah ada di sini, semuanya obat. Kalau beli di luar mah kita harus mengeluarkan uang lagi, biaya lagi di luar." (p5)

"Saya berharap tidak mengeluarkan biaya tambahan kaya yang lain-lain seperti penunjang, obat, rawat inap." (p12)

"Ya bahagianya itu, saya gak bayar 100\%." (p14)

\section{Pembahasan}

Berbagai penelitian sudah dilakukan untuk mendapatkan pelayanan kesehatan yang ideal yang dapat diterapkan pada tempatnya masingmasing. Pelayanan kesehatan berkualitas yang dapat memenuhi harapan pasien. ${ }^{13,14}$ Beberapa dimensi telah dikemukakan dari hasil penelitian terdahulu, namun terdapat perubahan penamaan kategori.

Infrastruktur merupakan dimensi yang akan menggambarkan penampilan fisik dari fasilitas pelayanan. $^{7}$ Pada penelitian, infrastruktur yang diubah menjadi sarana prasarana, diharapkan berbeda oleh pasien dari definisi yang telah ada. Mereka tidak terlalu mempermasalahkan penampilan fisik seperti desain bangunan, tetapi mereka lebih memperhatikan kelengkapan fasilitas tersebut, terutama pada obat-obatan. Kebersihan juga dinilai sebagai aspek penting karena beberapa informan juga berpendapat kebersihan identik dengan kesehatan. Hal lain yang menjadi pusat perhatian adalah kapasitas fasilitas akibat peningkatan kunjungan pasien ke rumah sakit di era Jaminan Kesehatan Nasional ini sehingga kapasitas menjadi hal penting dalam dimensi infrastruktur.

Kualitas personal mengacu pada kualitas tenaga kesehatan dalam menyediakan pelayanan. Keadaan ini meliputi ketanggapan, keandalan, keramahan, termasuk interaksi antara tenaga kesehatan dan pasien, serta perhatian. Sikap yang ramah dan empati juga menggambarkan kualitas dari personal. ${ }^{7}$ Dalam penelitian ini kualitas personel diubah menjadi karyawan. Pasien berharap petugas yang melayaninya berdaya tanggap cepat, kompeten, dan ramah, serta berempati. Kapasitas sumber daya pun menjadi hal penting karena hal ini berpengaruh pada kualitas personal sehubungan dengan 
peningkatan kunjungan pasien ke rumah sakit.

Pelayanan medis merupakan inti dari sebuah pelayanan. Hal ini mendeskripsikan kedalaman dan keluasan pelayanan. ${ }^{7}$ Namun, penggalian mengenai dimensi ini tidak mudah karena tidak banyak informan mengerti mengenai proses pelayanan. Satu-satunya hal yang diperhatikan dan diharapkan informan pada dimensi ini adalah komunikasi. Pasien berharap mereka mendapatkan informasi yang jelas dari berbagai aspek mengenai kesehatannya.

Pelayanan administrasi terdiri dari: proses sejak penerimaan pasien, perawatan, hingga pemulangan pasien. Dimensi ini juga mencakup kemudahan di dalam membuat suatu perjanjian jadwal pelayanan, kesederhanaan terhadap proses administrasi, serta waktu tunggu yang dibutuhkan pasien selama proses pelayanan. Banyak penelitian yang menunjukkan bahwa pasien tidak senang dengan waktu tunggu yang lama. ${ }^{7}$ Begitu pula pada penelitian ini, pasien mengharapkan pengurangan waktu tunggu di setiap pelayanan. Selain itu, pasien juga berharap ketertiban dalam prosedur administratif dan berharap tidak terdapat tindakan curang dalam proses administrasi.

Keamanan termasuk upaya minimalisasi risiko infeksi, efek samping yang membahayakan, dan bahaya lainnya yang berhubungan dengan pelayanan kesehatan. ${ }^{7}$ Beberapa informan berharap harus ada upaya mencegah potensi bahaya yang dapat terjadi pada pasien, seperti lantai yang licin maupun bahaya penularan penyakit.

Kepercayaan rumah sakit diukur dengan terdapatnya perasaan sejahtera yang dirasakan pasien saat berada di rumah sakit, yakni merasa aman dan terlindungi. ${ }^{7}$ Bagi pasien, kepercayaan ini dapat menimbulkan loyalitas rumah sakit dan juga memengaruhi pasien dalam memilih tempat berobat. Hal yang paling diperhatikan aspek ini adalah perbaikan keluhan pasien. Dengan ada perbaikan keluhannya maka pasien rela mengorbankan waktu dan tenaganya untuk menempuh rumah sakit tersebut.

Akses merupakan letak geografis dan jarak tempuh yang dibutuhkan untuk mencapai lokasi rumah sakit. ${ }^{8}$ Akses juga didefinisikan sebagai kemampuan dan ketersediaan untuk menempuh pelayanan kesehatan. ${ }^{18}$ Pasien berharap rumah sakit mudah dicapai baik menggunakan angkutan umum maupun angkutan pribadi. Selain itu, pasien juga berharap jalanan di sekitar rumah sakit tidak terhambat oleh kemacetan ataupun ukuran jalan yang terbatas.

Beberapa dimensi yang belum disebutkan pada penelitian sebelumnya di antaranya adalah kesetaraan antara pengguna Jaminan Kesehatan Nasional dan non-pengguna Jaminan Kesehatan Nasional, karena pasien merasakan diskriminasi dalam berbagai aspek di antara keduanya dan berharap hal tersebut seharusnya tidak terjadi. Selain itu, pasien juga memperhatikan bahwa pelayanan yang baik jangan hanya diperhatikan di suatu bagian saja, tetapi juga di seluruh bagian proses pelayanan sehingga terbentuk kualitas antarbagian yang baik. Hal yang penting lainnya adalah transparansi atau kejelasan informasi. Informasi yang tidak jelas dapat menyebabkan berbagai macam spekulasi dan juga prasangka buruk. Dalam era Jaminan Kesehatan Nasional ini, iur bayar juga merupakan dimensi yang diperhatikan karena kebanyakan masyarakat pengguna Jaminan Kesehatan Nasional ini merasa berkeberatan apabila harus menambah biaya dalam pelayanan kesehatannya.

\section{Daftar Pustaka}

1. Figueras J, McKee $M$, penyunting. Health system, health, wealth and societal wellbeing. New York: McGraw-Hill; 2012.

2. Omachonu VK, Einspruch NG. Innovation in healthcare delivery systems: a conceptual framework. Public Sector Innovation J. 2010;15(1):2-16.

3. Trisnawati K, Sumarni, Fudholi A. Analisis kepuasan pasien rawat jalan PNS pada masa pelaksanaan ASKES dan JKN. Jurnal Manajemen dan Pelayanan Farmasi. 2015; 5(1):33-9.

4. National Team for the Acceleration of Poverty Reduction. The Road to National Health Insurance (JKN). Jakarta: Office of the Vice President the Republic of Indonesia; 2015.

5. Pai YP, Chary ST. Dimensions of hospital service quality: a critical review, perspective of patients from global studies. Int J Health Care Quality Assurance. 2013;26(4):308-40.

6. Aagja JP, Garg R. Measuring perceived service quality for public hospitals (PubHosQual) in the Indian Context. Int J Pharmaceutical Health Care Marketing. 2010;4(1):60-83.

7. Padma P, Rajendran C, Lokachari PS. Service quality and its impact on customer satisfaction in indian hospitals, perspectives of patients and their attendants. Benchmarking an Int J. 2010;17(6):807-41.

8. O'Donnel 0. Access to health care in developing countries: breaking down 
demand side barriers. Cad Saude Publica. 2007;23(12):2820-34.

9. Zhao SH, Akkadechanunt T. Patients' perceptions of quality nursing care in a Chinese Hospital. Int J Nursing Midwifery. 2011;3(9):145-9.

10. Tahir M, Nawaz S, Butt MZ, Amin F, Mahmood KT. In-patient perceptions, needs, expectations, and satisfaction within tertiary care settings. J Pharm Sci Res. 2012; 4(12):2025-31.

11. Bleich SN, Ozaltin E, Murray CJL. How does satisfaction with the health-care system relate to patient experience. Bull WHO. 2009;87(1):271-8.

12. Lateef F. Patient expectations and the paradigm shift of care in emergency medicine. J Emerg Trauma Shock. 2011;4(2):163-7.

13. Bowling A, Rowe G, Lambert N, Waddington M, Mahtani KR, Kenten C, dkk. The measurement of patients' expectations for health care: a review and psychometric testing of a measure of patients' expectations. Health Technol Assess. 2012;16(30):3-8.

14. Wolf JA. Niederhauser V. Marshburn D. LaVela SL. Defining patient experience. Patient Experience J. 2014;1(1):7-19.

15. Lyons HZ, Bike DH, Ojeda L, Johnson A, Rosales R, Flores LY. Qualitative research as social justice practice with culturally diverse populations. J Social Action in Counseling Psychol. 2013;5(2):10-25.

16. Sabina Y, Khan FR. Triangulation research method as the tool of social science research. BUP J. 2012;1(1):154-63

17. Creswell JW. Research design: qualitative, quantitative, and mixed methods approaches Edisi ke-4. California: SAGE; 2014.

18. Jacobs B, Ir P, Bigdeli M, Annear PL, Damme WV. Addressing access barriers to health services: an analyticak framework for selecting appropriate interventions in low-income asian countries. Health Policy Planning. 2011;1(1):1-13. 